\title{
SOBERANÍA DE LA NACIÓN VS. SOBERANÍA DEL CATOLICISMO: INDAGACIÓN EN LA MEMORIA DEL ÚLTIMO ARZOBISPO ESPAÑOL EN SANTIAGO DE CUBA (1898-1899)
}

\author{
POR \\ María Elena Meneses Muro ${ }^{1}$ \\ Instituto de Historia de Cuba
}

RESUMEN

El artículo presenta un análisis del ministerio episcopal de Francisco Sáenz de Urturi y Crespo en la ciudad de Santiago de Cuba entre julio de 1898 y abril de 1899, a partir del procesamiento de fuentes documentales inéditas. La intención principal del texto es desentrañar las complejidades que caracterizaron su gestión de gobierno en un contexto marcado por el fin de la guerra independentista y los constantes enfrentamientos, no solo en el orden de la política y la religión, sino también en el universo cultural y simbólico que acompañaron los cambios.

PALABRAS CLAVE: Francisco Saénz de Urturi y Crespo; ministerio episcopal; nacionalismo; Santiago de Cuba; ocupación militar.

\section{SOVEREIGNTY OF THE NATION VS SOVEREIGNTY OF THE CATHOLICISM: INQUIRY IN THE MEMORY OF THE LAST SPANISH ARCHBISHOP IN SANTIAGO DE CUBA (1898-1899)}

\begin{abstract}
The article presents an analysis about the episcopal ministry of Francisco Saenz de Urturi y Crespo in the city of Santiago de Cuba between July 1898 and April 1899, through the processing of unpublished documentary sources. The main intention of the text is to unravel the complexities that characterized his government management in a context marked by the end of the independence war and the constant confrontations, not only in the order of politics and religion, but also in the cultural universe and symbolic that accompanied the changes.
\end{abstract}

KEY WORDS: Francisco Saénz de Urturi y Crespo; Episcopal Ministry; Nationalism; Santiago de Cuba; Military Occupation.

Cómo CITAR ESTE ARTículo / CITATION: Meneses Muro, M.a E. 2018. «Soberanía de la Nación vs. soberanía del catolicismo: indagación en la memoria del último arzobispo español en Santiago de Cuba (1898-1899)». Hispania Sacra 70, 142: 661-669. https:// doi.org/10.3989/hs.2018.045

$\begin{array}{ll}\text { Recibido/Received } & 11-10-2016 \\ \text { Aceptado/Accepted } & 24-01-2017\end{array}$

La evolución del gobierno arzobispal de Francisco Sáenz de Urturi y Crespo, ${ }^{2}$ a partir de la capitulación de las tropas

1 mmenesesmuro@gmail.com / ORCID iD: https://orcid.org/00000001-8675-5751

2 Francisco Sáenz de Urturi y Crespo -1842-1903- ocupó la silla arzobispal en Santiago de Cuba entre noviembre de 1894 y abril de 1899. Anterior a la fecha, el religioso franciscano se había distinguido por su destreza en las gestiones de gobierno eclesiástico como Vice Comisario General Apostólico de la Orden Franciscana en España -1884-1894y, posteriormente, como obispo de Badajoz -1891-1894-. Elementos que unidos a su experiencia pastoral en territorio americano, luego de españolas el 17 de julio de 1898 en la ciudad santiaguera, resulta de sumo interés para comprender la complicada trama que se teje entre religión, nacionalismo y política, culminando en la legitimación del derecho soberano del sacerdocio cubano sobre la mitra oriental.

integrar por trece años las misiones franciscanas en Bolivia -18711884-, acreditaron su designación al frente de la sede vacante en el oriente insular. Para mayor información biográfica, véase: Boletín Oficial del Arzobispado de Santiago de Cuba, 8: 70-73; Larrúa Guédes 2004, t. II: $15-30$. 
FIGURA 1

Francisco Sáenz de Urturi y Crespo, pintura exhibida en el Museo Catedral de Santiago de Cuba

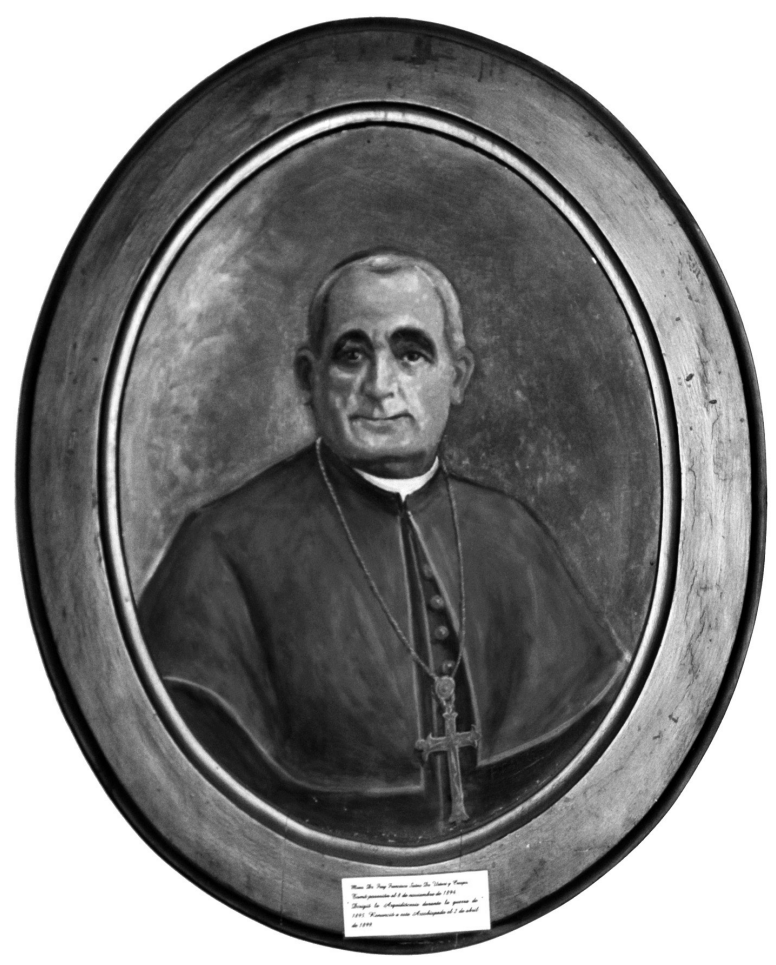

El gesto oficial de izar la enseña norteamericana se acompañó de un proyecto de transformación estructural de la sociedad que trajo consigo el cuestionamiento del entramado de costumbres y dogmas que sustentaban la cultura colonial. La institución eclesiástica - salvaguarda del orden peninsular - experimentó el estremecimiento del universo de prácticas católicas, privilegios religiosos, concepciones ideológicas, ético-morales y patrióticas hispanas sobre las que sostuvo su interacción con el conjunto de la sociedad durante cuatrocientos años.

Han pasado algo más de cien años y, aún hoy, la producción historiográfica en torno a la evolución de la Iglesia Católica en Santiago de Cuba durante los años postreros del siglo XIX, continúa circunscrita - como generalidad - a la conducta de la jerarquía católica ante la revolución independentista de $1895 .{ }^{3}$ Dentro del campo de estudios institucionales un conjunto de autores -en lo fundamental cubanos y españoles - han ahondado, con grados de profundidad variables, en el liderazgo eclesiástico, en tanto expresión de los debates del nacionalismo decimonónico, con énfasis en los enfrentamientos por la silla episcopal durante el período en que transcurre la ocupación militar de Estados Unidos (1899-1902). ${ }^{4}$

Desde luego, se trata de perspectivas de análisis importantes, sin embargo, estas no se adentran, de manera sistemática, en la complejidad que supuso regir la Iglesia Católica en el tiempo vertiginoso que sucedió al cierre de la dominación española en 1898.

3 Véanse los acercamientos pioneros: González del Valle 1918; Roig de Leuchsenring 1958.

4 Suárez Polcari 1996 y 2003; Larrúa Guédes 2004; Hernández Suárez 2010; Segreo Ricardo 2010; Uría 2016.
Mención aparte merece la reveladora obra del sacerdote jesuita Manuel Maza Miquel, sin dudas, la aproximación más completa a la historia eclesiástica en la segunda mitad del siglo XIX e inicios del XX. ${ }^{5} \mathrm{El}$ examen de fuentes provenientes del Archivo Secreto del Vaticano le posibilitó la incorporación de elementos de análisis válidos para el conocimiento de la urdimbre de conflictos que agitaron a la institución religiosa en Cuba durante el contexto transicional en las postrimerías de la centuria decimonónica. Asimismo, el hecho de incorporar un valioso cuerpo documental a modo de anexos permite el acceso a materiales íntegros de indudable valor para su procesamiento por parte de especialistas interesados en determinadas problemáticas sobre el tema.

El presente artículo tiene como objetivo esencial aportar una mirada del mismo proceso, pero desde la interioridad emocional y puntos de vista del exponente más representativo del alto clero español en la isla. Cada tópico en que se estructura el texto transcurre de la mano del arzobispo franciscano, testigo excepcional de un cambio de dominio político y, por consiguiente, de la emergencia de nuevas racionalidades discursivas y formas diversas de asumir, tanto en las altas esferas de la política como en la cotidianidad de la sociedad santiaguera, los signos culturales que marcaban los nuevos tiempos. Con el propósito de desentrañar las complejidades que caracterizaron la evolución de su ministerio episcopal, se procesaron valiosos materiales documentales, en su mayoría inéditos y, en especial, las «Memorias de Cuba» existentes en el Fondo Personal de Francisco Sáenz de Urturi y Crespo del Archivo del Convento de Zarauz, en España. ${ }^{6}$

Se trata, por consiguiente, de avanzar en otras aristas menos recurrentes. Imposible agotar todas las posibilidades de análisis. El texto se inserta dentro de una línea de investigación, con otras interrogantes tendientes a aprehender en su mayor dimensión la complejidad de los debates en el seno de la Iglesia Católica, sus relaciones con otras instituciones, religiosas y laicas, la historia comparada con las dinámicas operadas en otros reductos coloniales hispanos, pero también los modos en que este proceso transicional se asumió en los intersticios de la sociedad poscolonial.

\section{¿POR QUIÉN DOBLAN LAS CAMPANAS?}

Desde el establecimiento del nuevo poder político en la ciudad de Santiago de Cuba, ${ }^{7}$ las directrices del presidente de los Estados Unidos William McKinley resguardaron las edificaciones de significación histórico-cultural. Dentro de esa línea de acción, quedó prohibida toda destrucción intencional - «excepto cuando lo exija urgente necesidad militar»- de las iglesias y edificios dedicados al culto religioso, ${ }^{8}$ lo que no implicó compromiso de patronazgo para las autoridades

\footnotetext{
5 Maza Miquel 1997.

6 Agradezco al Dr. Edelberto Leiva Lajara, por proporcionarme esta valiosa fuente documental y por los intercambios de ideas sostenidos en torno a la investigación.

El 18 de julio de 1898 Leonard Wood fue nombrado gobernador militar de la plaza santiaguera y, posteriormente, comandante general de la provincia, iniciándose de este modo el período de Ocupación Militar Norteamericana en la región oriental.

8 La proclama del presidente William McKinley fue publicada en la ciudad de Santiago de Cuba el 20 de julio de 1898. Para la consulta del texto íntegro, véase: Bacardí y Moreau 1924, t. X: 128-129.
} 
norteamericanas. De hecho, las relaciones del nuevo régimen con la Iglesia Católica quedaron delimitadas - al menos legalmente- el 20 de octubre de 1898 con la Constitución Provisional del gobernador Leonard Wood. De manera oficial, concluyó la preeminencia religiosa e ideológica que ostentó la Iglesia en los espacios de la vida insular durante la era colonial. La institución eclesiástica fue separada del Estado y se estableció la libertad de culto. ${ }^{9}$

De tal suerte, los capellanes del cementerio, de la cárcel y del hospital fueron suprimidos. Se le quitó a la Iglesia la franquicia del correo para los pliegos oficiales y se les exigió el franqueo como a todos los demás. El 15 de diciembre de 1898, Sáenz de Urturi le expresaba a Mariano Rampolla - secretario de Estado del Vaticano 1887-1903- sus impresiones sobre las determinaciones de los ocupantes norteamericanos. Sentenciaba que, para los ocupantes, "los señores curas y el Arzobispo, en calidad de tales, nada [eran]»; con perspicacia avizoraba que no tardarían en llegar "las leyes a sancionar todo esto y desaparecerá la vida oficial de la Iglesia». ${ }^{10}$

No obstante, fue otro gesto gubernamental, encabezado - curiosamente- por oficiales de las filas del Ejército Libertador, el que acentuó la dinámica en la interacción con la institución eclesiástica. En la noche del 30 de noviembre, los salones de la Casa municipal se iluminaron para dar inicio a la primera sesión de la Asamblea de Vecinos bajo la presidencia de Emilio Bacardí y Moreau, ${ }^{11}$ recién nombrado Mayor de la Ciudad por el gobernador Leonard Wood. ${ }^{12}$ La alcaldía de Bacardí -noviembre1898-julio1899- significó el reordenamiento político para llevar la nombrada «era de paz y libertad» hacia la civilización moderna. En este sentido, comenzó un proceso de laicización de la sociedad santiaguera que obedeció a la vertebración de la voluntad nacionalista del alcalde y la noción de progreso vinculada a la cultura norteamericana. La presencia cercana de las autoridades interventoras representó la interrelación con las influencias de la modernidad capitalista y el paradigma político, atractivos para la construcción de la República cubana.

Desde la propia acta inaugural comenzó el desmontaje de las denominaciones representativas del colonialismo, lo cual es significativo si partimos de la imbricación de la Iglesia Católica en ese universo simbólico. Acorde con

\footnotetext{
9 Pichardo 1973, t. I: 518-519.

10 Maza Miquel 1997: 328.

11 Emilio Bacardí y Moreau -1844-1922- estuvo vinculado al movimiento conspirativo en Santiago de Cuba desde su juventud. Con el inicio de la Guerra Necesaria se integró al movimiento clandestino de la ciudad. Como consecuencia de sus actividades, fue encarcelado en 1896. Para mayor información, véase: Castellanos 1950.

12 Libro de Actas del Consejo de Vecinos, Archivo Provincial de Santiago de Cuba (APSC), Sesión del 30 de noviembre de 1898. Debe resaltarse la amplia libertad que gozó la administración local durante aquella época extraordinaria, aspecto que merece una mayor atención por parte de los especialistas en el campo de la historia regional. El municipio de Santiago de Cuba, independiente de La Habana, se convirtió en un órgano autónomo. Como no existían leyes que regulasen la administración municipal el alcalde Emilio Bacardí se regía, según sus palabras, "por su sano juicio y criterio» a la hora de legislar sobre los asuntos locales. De hecho, la única autoridad a la cual se subordinaba era el gobernador militar Leonard Wood con el que, por cierto, mantuvo excelentes relaciones. Véase: «Declaración sobre la época en que fue nombrado Mayor de la Ciudad de Santiago de Cuba por el Gobernador Militar L. Wood», Museo Emilio Bacardí de Santiago de Cuba, Emilio Bacardí, leg. 31, no. 3. f. 2.
}

la era "independiente", fue transmutada una toponimia religiosa que representaba la sociedad colonial: el Cementerio General de Santa Ifigenia pasó a denominarse solo Cementerio General y la simbología independentista sustituyó la calle de la Providencia por Maceo y la Plaza de Santo Tomás por Flor Crombet. Con la voluntad patriótica convivió - en este caso- el gesto de agradecimiento a la autoridad norteamericana. Así, la calle San Tadeo fue rebautizada como Leonardo Wood. ${ }^{13}$

La política civil se dirigió a suprimir las prerrogativas de la Iglesia Católica en el espacio postcolonial y los privilegios sociales en correspondencia con las profesiones religiosas. En vista de ello, se eliminaron las diferenciaciones en las sepulturas del Cementerio General, al refundirse en "uno solo los departamentos civil y católico», y se prohibieron "los enterramientos en el patio o en cualquier otro lugar del Convento de Monjas $» .^{14}$ Las personas que falleciesen en dichas edificaciones estaban sujetas en lo sucesivo a la nueva política gubernamental.

Las campanas de las iglesias constituían un símbolo representativo de la preeminencia religiosa del catolicismo sobre la esfera pública. Sus toques anunciaban a toda la población los actos del culto y sus repiques decretaban la solemnidad de las fiestas y procesiones religiosas. Por lo cual no es de extrañar que en torno al ejercicio de poder sobre los repiques de campanas se detonara la primera confrontación entre la autoridad municipal y el arzobispo, quien hasta ese momento se mantenía al margen de la actividad gubernativa.

Para el prelado, el alcalde, «bajo el pretesto de que impedían el reposo de los ciudadanos [...] quería señalar cuando se habia de replicar y el tiempo q. Ios repliques habían de durar (sic)». ${ }^{15}$ Sin embargo, la oposición del franciscano, que hizo valer su autoridad religiosa, proporcionó que las iglesias de la ciudad continuasen doblando según la costumbre colonial durante su prelacía. ${ }^{16}$

La voluntad de Bacardí, si bien respondió a las quejas formuladas por los moradores, contenía una clara implicación política en consonancia con el nuevo modelo de sociedad. El espacio público comenzaba a laicizarse y el privilegio del culto católico no se correspondía con la igualdad religiosa que se había inaugurado. Los toques litúrgicos se convirtieron en un conflicto agudo que develó con intensidad la tendencia liberal de la nueva política municipal. En uno de los oficios enviados por Emilio Bacardí al arzobispo Francisco de Paula Barnada -1899-1913-, sucesor de Sáenz de Urturi, se evidencia la lógica de pensamiento del alcalde con respecto a la irrevocabilidad de la igualdad religiosa:

13 Véase: «Libro de Actas del Consejo de Vecinos», APSC, Sesión del 30 de noviembre de 1898, Sesión del 13 diciembre de 1898, Sesión de marzo de 1899; Hernández, José Joaquín. 1924. "Santiago de Cuba en 1898. Memorias de un bloqueado», en Emilio Bacardí y Moreau: 370. Para un análisis detenido de la reescritura toponímica, véase Iglesias Utset 2003: 150-173.

14 "Libro de Actas del Consejo de Vecinos», APSC, Sesión del 30 de noviembre de 1898; Bacardí y Moreau 1924: 199.

15 "Memorias de Cuba», Archivo del Convento Zarauz, Guipúzcoa (ACZ), Fondo Personal de Francisco Sáenz de Urturi y Crespo, f.32.

16 Las desavenencias entre las autoridades civil y eclesiástica por motivo de los repiques de las campanas no se resolvieron hasta 1901 cuando la Iglesia, bajo la gestión arzobispal de Francisco de Paula y Barnada, se readecuó a las disposiciones del Alcalde Municipal. 
Es una gran inconveniencia de razón y de lógica que (las personas) tengan que aceptar las molestias que le producen creencias que, si bien son de respetarse porque son secuela natural de una fe religiosa; pugnan contra la libertad de cultos, contra la libertad individual que no admite molestias de otro, así como se las proporciona. ${ }^{17}$

Resulta interesante el significado simbólico que cobran las campanas en la representatividad de la Iglesia para ambos regímenes políticos. Bajo la dominación hispana, las campanas de los templos eran uno de los emblemas que representaban la simbiosis entre el poder político y la Iglesia Católica, sus repiques daban aviso solemne a las juntas del Ayuntamiento y la llegada de los capitanes generales a las ciudades. Con la inauguración de la dominación norteamericana, separada la Iglesia del Estado, pasaron a ser motivo de molestias ciudadanas y amenaza para la proclamada libertad religiosa.

El cuestionamiento de la exhibición pública del culto se manifestó también en el caso de las procesiones religiosas de los entierros. Según refiere en el arzobispo metropolitano ${ }^{18}$ en sus Memorias, la autoridad civil trataba «de oponerse a que la cruz acompañase a los cadáveres al ser conducidos al cementerio, y de que los sacerdotes fuesen rezando por las calles en estos casos ${ }^{19}{ }^{19}$ La ruptura oficial con la tradición religiosa de la era colonial tampoco se concretó en este caso, pues el prelado no cedió en su defensa de una de las manifestaciones religiosas de mayor connotación social. No obstante, la ofensiva contra las procesiones en general continuó y alcanzó también el plano de los cuestionamientos populares. En septiembre de 1899, la Secretaría de Estado recibió una demanda de un habitante de Santiago de Cuba que solicitaba la prohibición de las procesiones religiosas y la salvaguarda de la libertad de cultos. ${ }^{20}$

Las valoraciones sobre el conjunto simbólico que representaba a la Iglesia alcanzaron otros ribetes cuando se trató de la selección y organización de la memoria histórica regional. Así lo expresó Emilio Bacardí en su proyecto de aunar «reliquias históricas [...] provenientes de nuestras guerras de independencia», con motivo de la construcción de un Museo-Biblioteca. ${ }^{21}$ Lo cierto es que su iniciativa, si bien obedeció a un imperativo de legitimación de la identidad patriótica, preservó, al mismo tiempo, el patrimonio artístico de Santiago de Cuba, incluyendo -en su criterio- la cultura material de la institución eclesiástica.

17 «Expediente formado con motivo de comunicaciones recibidas de la Alcaldía Municipal de esta ciudad sobre el toque de campanas», Archivo Histórico Arquidiocesano de Santiago de Cuba (AHASC), Gobierno, Serie Hospitales, Asilos, Conventos e Instrucción, leg. 28, no. 7. f. 3.

18 El 24 de noviembre de 1803 el Papa Pío VII, por la bula In universalis Ecclesiae regimine, elevó la sede episcopal de Santiago de Cuba a metropolitana. En su calidad de arzobispado, sufragaba las diócesis de La Habana y San Juan de Puerto Rico. Las tres sedes formaban una Provincia Eclesiástica cuya dignidad correspondía al arzobispo de la mitra santiaguera, quien por derecho era senador del Reino español y subdelegado castrense. Véase: Episcopologio de la Iglesia Católica en Cuba. Catálogo cronológico por diócesis, en: http://www.catholic-hierarchy.org/. Consultado el 2 de mayo de 2012.

19 "Memorias de Cuba», ACZ, Fondo Personal de Francisco Sáenz de Urturi y Crespo, f. 32.

20 Iglesias Utset 2003: 66

21 Bacardí y Moreau 1924: 213.
Entre los meses de diciembre y febrero de 1899, a solicitud de la autoridad municipal se produjo un intercambio de comunicaciones entre este, el arzobispo y los capellanes de las iglesias de la ciudad, que propició las donaciones religiosas a la institución en cuestión.

La creación del Museo-Biblioteca constituye un ejemplo que trasluce la incidencia de los cambios políticos sobre la Iglesia. El sentido propio de las instituciones religiosas fue transgredido ante el sentido público que tomaron las edificaciones. La "democratización" de la sociedad, ya excolonial, no solo demandó la apropiación social de los parques y las plazas, ${ }^{22}$ sino también, la apertura del patrimonio de las iglesias fuera de los dominios eclesiásticos. Según afirma Sáenz de Urturi, el alcalde manifestaba que "las iglesias eran establecimientos públicos; no eran ni tan siquiera de los católicos, sino que pertenecían al pueblo, y que él, en su calidad de Alcalde era el llamado a mirar por la conservación de cuanto podía ser una gloria de Santiago ${ }^{23}{ }^{23}$

Las anteriores expresiones - si bien puestas en boca de Bacardí por el arzobispo- no resultan del todo desacertadas, puesto que, en el proceso de pesquisa, aquel no se contentó con obtener información sobre las propiedades eclesiásticas, sino que visitó personalmente las iglesias y dirigió la búsqueda de objetos de valor museable. ${ }^{24}$ Actitud que el prelado impugnó, al menos en su pensamiento, pues para él no era legítima la investigación sobre el patrimonio religioso de la Iglesia. ${ }^{25}$ En este sentido, si la autoridad civil, bajo el colonialismo, representó para el prelado la limitación de la jurisdicción religiosa y social de la Iglesia, con la llegada de Bacardí simbolizó el quebranto definitivo de la oficialidad eclesiástica.

Por cierto, es importante resaltar que las donaciones realizadas al Museo-Biblioteca no poseían una connotación religiosa con respecto al culto, sino artístico-histórica. En las orientaciones establecidas por el arzobispo a los capellanes de las iglesias, les hizo explícito que la colaboración con el alcalde no podía afectar los intereses de sus instituciones, debía constar que los objetos eran propiedad de la Iglesia «por si algún día no creyéndolo necesario y quieren deshacerse de él», pueda la institución eclesiástica «reclamarlo y obligar a que se le sea devuelto como propietaria». ${ }^{26}$

El 12 de febrero de 1899, en gesto cortés (como parte del protocolo), el arzobispo Sáenz de Urturi asistió al acto de inauguración del Museo-Biblioteca, que contó con la presencia del gobernador militar Leonard Wood y, por supuesto, el alcalde Emilio Bacardí. Convergían todos entonces, curiosamente, en el espacio creado con el fin de preservar un patrimonio histórico que parecía unir lo hispano, lo cubano y también, en alguna medida, lo norteamericano.

22 Para ahondar en la transformación de los espacios públicos durante el período interventor, véase: Iglesias Utset 2003: 34-46; Meza 1902.

${ }^{23}$ "Memorias de Cuba», ACZ, Fondo Personal de Francisco Sáenz de Urturi y Crespo, f. 32.

${ }^{24}$ Véase: «Sobre algunos objetos pertenecientes a las Iglesias facilitados al Museo en esta Ciudad», AHASC, Gobierno, Serie Hospitales, Asilos, Conventos e Instrucción, leg. 28, no. 2, f. 2.

25 «Memorias de Cuba». ACZ, Fondo Personal de Francisco Sáenz de Urturi y Crespo, f. 32.

26 «Sobre algunos objetos pertenecientes a las Iglesias facilitados al Museo en esta Ciudad», AHASC, Gobierno, Serie Hospitales, Asilos, Conventos e Instrucción, leg. 28, no. 2. f. 4. 
A partir de la reestructuración institucional que trajo consigo el cambio de poderes políticos, comenzó la investigación sobre las propiedades del Estado. Las posesiones eclesiásticas también fueron objeto de interés para el acalde Emilio Bacardí, ${ }^{27}$ y constituyeron el núcleo de tensión más importante entre el arzobispo Sáenz de Urturi y el gobernador municipal, en lo relativo al derecho de posesión sobre el edificio del Convento de San Francisco. ${ }^{28}$

Entre los primeros acuerdos de la Asamblea de Vecinos se situó la demolición del denominado Cuartel de San Francisco. Partícipe de un proyecto de obras públicas, sus materiales serían empleados en la «terminación de la fachada del Cementerio, arreglo de las calles del Tivolí y la Calzada de Cristina, hasta la entrada del Cobre». ${ }^{29} \mathrm{El}$ hecho físico de la demolición se convirtió en un símbolo que legitimó el «discurso patriótico». Según relata Sáenz de Urturi, el alcalde declaró que el edificio "era del pueblo» y en nombre de él "tomaría posesión», destinando aquella manzana "para el desahogo de la Capital». ${ }^{30}$

Ante la voluntad política que expresaba la actitud de Bacardí y ante el peligro real de que predominara sobre el interés eclesiástico, Sáenz de Urturi solicitó la protección americana. En una entrevista con el gobernador militar Leonard Wood - referida en sus Memorias-, defendió el derecho de la Iglesia Católica sobre la edificación: presentó la Real Orden de devolución de la misma, hizo alusión a la proclama de Mckinley del 20 de julio anterior e incluso, "le [dijo] que si no [le] amparaba en su derecho, iría en persona a pedírselo al presidente de la Republica». ${ }^{31}$ Lo cierto es que la respuesta de Wood, a favor de los argumentos del arzobispo, deshizo el plan del Ayuntamiento y protegió, para la Iglesia Católica, una de las propiedades más relevantes que poseía en la ciudad. La victoria de Sáenz de Urturi puede considerarse como un caso singular, contrario a la demolición de cuarteles y otras edificaciones militares que caracterizó el mapa urbano de la isla por aquellos meses.

No obstante, la autoridad civil no cejó en su interés por las posesiones eclesiásticas, llegando incluso a interrogar los derechos sobre el Palacio arzobispal que figuraba como propiedad de la Iglesia en el registro antiguo de la propiedad. ${ }^{32}$ Con respecto a la autoridad civil sobre las instituciones católicas, es importante destacar que en el marco de la comisión de paz celebrada en París, el delegado

27 El conflicto en torno al derecho de la Iglesia Católica sobre las propiedades eclesiásticas tuvo su punto de mayor inflexión bajo el gobierno arzobispal de Francisco de Paula Barnada y Aguilar.

28 La Iglesia y Convento de San Francisco fue fundada en 1515 por la Orden de los Franciscanos. Durante la contienda bélica de 1895 el convento fue ocupado por militares españoles. En agosto de 1898, la orden religiosa marchó de la isla dejando su custodia al arzobispo Sáenz de Urturi. En el acta de entrega a la congregación, de regreso en la ciudad a finales del mismo año, se especificó que ningún prelado estaba autorizado para inquietar a dicha congregación de la posesión de la Iglesia y sus terrenos. "Iglesia de San Francisco», AHASC, Gobierno, Serie Religiosos, leg. 14, nos. 1,2 y 3 y leg. 25, no. 4.

29 "Libro de Actas del Consejo de Vecinos», APSC, Sesión del 30 de noviembre de 1898 .

30 "Memorias de Cuba», ACZ, Fondo Personal de Francisco Sáenz de Urturi y Crespo, f. 33.

31 Ibídem, f. 35.

32 «Palacio Arzobispal», APSC, Gobierno Municipal. apostólico Placide Chapelle ${ }^{33}$ había logrado la protección de las propiedades eclesiásticas en las excolonias españolas.

Las divergencias entre el arzobispo y la autoridad municipal fueron, sin duda, reflejo de los choques inevitables en las nuevas circunstancias de presupuestos socio-políticos antinómicos que se debatían en los espacios institucionales. En esas circunstancias, las manifestaciones de Sáenz de Urturi en defensa de los intereses eclesiásticos pueden presentarse como evidencia de oposición a la política progresista de la autoridad municipal, pero, contextualmente, expresan el resultado lógico de una necesidad de autopreservación de la institución encarnada coherentemente por el prelado. Paradójicamente, las autoridades representativas del paradigma de modernidad, en la persona de Leonard Wood, legitimaron de inicio esas aspiraciones en una actitud que, si bien susceptible a múltiples lecturas, no puede dejar de entenderse como parte de la política dirigida a poner límites al goce de la recién estrenada "libertad" de los cubanos.

En el informe que presentó el delegado apostólico al cardenal Mariano Rampolla sobre la situación de la Iglesia Católica en la ciudad de Santiago de Cuba el 25 de febrero de 1899, resalta su conversación con el general Wood. Según afirmaciones de Chapelle, este último le había comentado que si él lo permitiera, los cubanos demolerían las iglesias para pavimentar las calles con las piedras de los edificios sagrados y que no se inquietarían con escrúpulos al confiscar todos los bienes de la Iglesia. ${ }^{34}$ Amén de la imagen conciliadora que pretendió presentar el gobernador militar ante el representante del Vaticano, el suceso de San Francisco demuestra que sus afirmaciones guardaban algo de veracidad, al menos, en el terreno de la política municipal.

En cuanto al arzobispo, más allá de ámbitos institucionales, se vio enfrentado también al rejuego de las emociones nacionalistas en los espacios públicos. De hecho, los desafíos pastorales alcanzaron proporciones inusitadas ante la deslegitimación pública de su autoridad.

\section{ENTRE DOS CLEROS: DEBATES POR UNA IGLESIA CUBANA}

La "nueva era" se vivía desde la indefinición, la incertidumbre por el futuro inmediato y la impaciencia por el florecimiento de la nación cubana. Sin embargo, según expresó un testigo de la época: "no se era ya español». ${ }^{35}$ Una de las mayores certezas estribaba en la urgencia de la subversión del orden colonial para dar término al "período transitorio». La evacuación de las tropas españolas encarnaba la ansiada culminación de la gobernación colonial, y, a la vez, un paso importante para regenerar las energías del país mediante «la confianza que crea un orden perfecto y una paz segura». ${ }^{36}$ En el imaginario santiaguero, tal procedimiento estuvo indisolublemente ligado con la salida de las autoridades coloniales. De ahí que se comprendan parte de las actitudes

33 Monseñor Chapelle, arzobispo de Nueva Orleans, fue nombrado delegado apostólico para Cuba y Puerto Rico el 19 de septiembre de 1898. Para mayor información, véase: Segreo Ricardo 2010: 319-320.

34 Carta de Placide Chapelle al cardenal Rampolla. Tomada de: Maza Miquel 1997: 506.

35 Hernández, José Joaquín; «Santiago de Cuba en 1898. Memorias de un bloqueado», en Bacardí y Moreau 1924: 373.

36 La Independencia, 2: 2-3. 
generadas ante la permanencia del arzobispo Sáenz de Urturi, último representante de la dominación en marchar de la capital oriental.

El complejo proceso descolonizador que comenzó a dilucidarse en el fin de siglo tuvo profundas expresiones en el plano de la psicología social. Los elementos todos manifestaron diversas actitudes, que iban desde la conciliación con el elemento español hasta su rechazo; en ellas cobró relevancia el compromiso contraído con el régimen colonial. Derribada la censura española, a partir de agosto de 1898 comenzó a surgir una variada gama de publicaciones desde las cuales se fortaleció abiertamente la conciencia patriótica.

Las publicaciones periódicas que circularon en la ciudad fueron medulares en el cuestionamiento de la autoridad del arzobispo español durante los meses finales de su episcopado. El 15 de septiembre de 1898 Sáenz de Urturi remitió al cardenal Rampolla un recorte de dichas publicaciones para reafirmar que su permanencia en la isla se hacía insostenible. La solicitud de fondos que hizo a las autoridades americanas fue interpretada por los auto-catalogados "libre pensadores" como dinero "para seguir viviendo a pan y manteles». El "politican" que se había quedado en su diócesis "a pesar» de la capitulación, debía vivir «de su trabajo, de las misas, de sus rezos, o del ayuno y la penitencia, que era su deber $"{ }^{37} \mathrm{El}$ descrédito social del prelado evidencia no solo el ambiente de tensión, sino los obstáculos que le rodearon para desarrollar su proyecto de gobierno en un contexto marcado por la desvertebración de la red parroquial, sobre todo en las zonas rurales. De hecho, en una de las correspondencias el franciscano expresó al cardenal Rampolla que encaminaría su ministerio hacia la reconstitución del arzobispado, sin embargo, le fue imposible recabar fondos para esta empresa o cualquier otra.

En cuanto a las solicitudes hechas al general Shafter, fueron desestimadas las nóminas de los salarios del clero que le envió el arzobispo y, posteriormente, el general Wood recibió una comunicación del gobierno americano en la que se le orientaba que no debía pagar la menor indemnización al prelado. En los últimos tres meses, el clero no recibió sus salarios. Sáenz de Urturi previó que podía solventar sus gastos solo dos meses. ${ }^{38}$ Esta precariedad financiera constituyó todo un reto a la hora de satisfacer los servicios religiosos en la Catedral Metropolitana, pues contaba únicamente con dos capitulares a los que no podía pagar, dado que la edificación solo tenía deudas. La situación del Cabildo se evidenció cuando el sacerdote español Anastasio Miguel Martínez solicitó la restitución de los 1347 pesos con 89 centavos que se le debían por su desempeño como capellán administrador del Cobre entre 1896 y $1898 .^{39}$ Sin embargo, según refiere Sáenz de Urturi en sus Memorias, durante el resto de su episcopado el coro de la Catedral no se interrumpió un solo día; con cuatro sacerdotes logró que

37 Carta de Francisco Sáenz de Urturi al cardenal Rampolla. Tomada de: Maza Miquel 1997: 325. Para una visión de conjunto sobre los principales cuestionamientos expuestos por el prelado español, véase: "Memorias de Cuba», ACZ, Fondo Personal de Francisco Sáenz de Urturi y Crespo, ff. 23-24.

38 Véase: Suarez Polcari 2003: 178.

39 "Libro de Acuerdos del Ilustrísimo Cabildo en las Sesiones», AMCSC, f. 191. la Basílica no cerrase sus puertas y se oficiasen dos misas, la parroquial a las 7 y la conventual a las $9 .{ }^{40}$

Otra expresión del sentimiento nacional fue la divulgación de volantes que promovían diversas figuras del independentismo para los cargos públicos de la futura nación. El 10 de agosto de 1898 Sáenz de Urturi le remitió uno de los impresos al cardenal Rampolla y al reverso lo hizo partícipe de su preocupación: «los cubanos pensaban expulsar del país a todo el elemento español». En la "Candidatura del Pueblo de Cuba. REPÚBLICA CUBANA»"1 figuraba junto a los nombres de Bartolomé Masó, Máximo Gómez y Calixto García, el del sacerdote cubano Luis Alejandro Mustelier y Galán, ${ }^{42}$ destinado para ocupar la mitra santiaguera. En la carta al secretario del Vaticano expuso que todo lo que a España recordaba era «objeto de rechifla y de desprecio», preveía no poder ni predicar ni escribir «pues a todo (decían), - antiguallas españolas». La renuncia del prelado no consta en la carta, más sostuvo que su gestión arzobispal se hacía estéril y podía perjudicar los intereses religiosos de la isla. ${ }^{43} \mathrm{El}$ franciscano atinaba sobre lo dificultoso que le sería permanecer en un espacio que afirmaba la independencia sobre el desmantelamiento de la representatividad metropolitana. De manera sutil instaba a las autoridades vaticanas a que reflexionasen sobre el futuro de la arquidiócesis santiaguera.

Mientras tanto, la voz independiente del clero cubano se hizo sentir el 8 de septiembre de 1898. A menos de un mes de haber capitulado la ciudad, se celebró la primera fiesta religiosa en "Cuba Libre e Independiente». En el Santuario del Cobre, militares cubanos y americanos asistieron a la misa oficiada por el sacerdote independentista Desiderio Mesnier de Cisneros. ${ }^{44}$ La festividad expresaba la transformación de los espacios religiosos una vez terminada la relación colonial. El Santuario, plaza militar para la defensa del régimen colonialista, se convirtió en un símbolo de la conciencia patriótica cubana. El catolicismo figura como centro de la prédica, más las expresiones simbolizan una suerte de «mutación patriótica» del discurso católico. Si durante el señorío colonial la jerarquía española se dispuso a salvaguardar el régimen monárquico sentando la sociedad sobre la "Soberanía Social" del catolicismo, la homilía del

40 "Memorias de Cuba», ACZ, Fondo Personal de Francisco Sáenz de Urturi y Crespo, f. 22.

41 La fecha del volante data del 15 de abril de 1898. Para su consulta, véase: Maza Miquel 1997: 322-323.

42 Sacerdote santiaguero simpatizante con la causa independentista. Ocupaba el cargo de Prebendado de la Santa Basílica Metropolitana, pero desde 1895 estaba de licencia y se encontraba en México. Para mayor información, véase: «Expediente de Mustelier y Galán», AHASC, Gobierno, Serie Clero, leg. 37, no. 73.

43 En la misma carta, Sáenz de Urturi hace explícita la necesidad de visitar al Papa León XIII para darle cuenta del delicado estado en que se encontraba la arquidiócesis. El 31 de agosto llegó a manos del arzobispo la respuesta de Mariano Rampolla: según resolución de la Santa Sede, debía permanecer en la dirección del Arzobispado y esperar la llegada del Delegado Apostólico. Véase: Maza Miquel 1997: 322-323.

44 Natural del poblado de Santiago del Prado del Cobre. En 1869 fue expulsado del Colegio Seminario San Basilio El Magno por su simpatía con la causa independentista y, posteriormente, se unió a las fuerzas del general Silverio del Prado. Desde el 30 de agosto de 1891 era el cura párroco de Nuestra Señora de los Dolores. En opinión de Urturi, Mesnier era la figura principal del clero cubano en tormo al que se nucleaban los demás sacerdotes independentistas. Para mayor información, véanse: Maza Miquel 1997: 246-248; González del Valle 1918: 163. 
sacerdote cubano, partícipe del lenguaje progresista, tenía por centro consolidar una "República Cristiana" a través de las enseñanzas de la Virgen de la Caridad. ${ }^{45}$

Al tiempo que la prédica de Mesnier invadió uno de los lugares más relevantes de la religiosidad popular, varios clérigos enviaron una carta al Papa León XIII solicitando de su Santidad el nombramiento de sacerdotes cubanos para los episcopados de Santiago de Cuba y La Habana. La petición se basó en la suposición de que los padres Mustelier y Dobal serían los candidatos que el nuevo gobierno presentaría a la Santa Sede. ${ }^{46}$

La reacción del arzobispo ante la insubordinación del clero no rebasó los marcos de una reunión celebrada en el Palacio arzobispal en el mes septiembre. Su actitud perspicaz buscó la subordinación clerical al plantear la necesidad de un entorno favorable para los intereses insulares, pues la «actitud hostil» a su autoridad solo conducía «a que la Sta. Sede se persuadiese de que entre ellos no habría quien pudiese ponerse al frente de la Diócesis». La llegada del Delegado Apostólico era el momento oportuno para «trabajar» en la admisión de su renuncia y el nombramiento de un «hijo de Cuba». ${ }^{47}$ La «entera sumisión» que ofreció la clerecía, quedó reducida al compromiso.

La soledad del franciscano ante la emigración de su cuerpo sacerdotal contrastaba con la cohesión de los insulares que pugnaban por el protagonismo clerical. En agosto de 1898 la mayor parte del clero español, tanto regular como secular, había marchado de la ciudad. Con la partida del vicario general del arzobispado Felipe Fuero y Jiménez y del secretario de Cámara y Gobierno Feliciano García Fernández, figuras relevantes en las cuales se apoyaba para la administración arquidiocesana, el prelado quedó sin colaboración para tomar sus determinaciones. ${ }^{48}$ Por lo tanto, todas las acciones de Sáenz de Urturi estuvieron marcadas por su iniciativa personal. La culminación del patrocinio estatal propició la interrupción de las comunicaciones entre el gobierno español y el arzobispo y generó una situación inédita, en la que el cambio, desde la perspectiva de un sacerdote español, solo podía enfrentarse con incertidumbre. Las solicitudes de instrucción al ministro de Ultramar sobre la conducta que debía asumir con el clero de la arquidiócesis nunca fueron atendidas y las orientaciones del secretario del Vaticano se limitaron a su permanencia al frente de la mitra oriental.

Uno de los documentos más relevantes del 98 decimonónico para esclarecer el rechazo del clero cubano hacia obispos españoles así como sus argumentos para legitimar el derecho a la preeminencia eclesiástica, lo constituye el "Manifiesto del Clero Cubano Nativo» dirigido "al Muy

45 Los representantes cubanos estaban integrados por el general Agustín Cebreco y Sánchez junto a su Estado Mayor. El sacerdote español Andrés Ramírez Cobos hizo acto de presencia en su calidad de capellán del Santuario. «Acta de la primera festividad religiosa en Cuba independiente», AMCSC, en exposición.

46 Entre las firmas estampadas en dicho documento se encuentran las de Ernesto Lecuona, Manuel Gonzáles, Francisco Daniel y José Gómez. Maza Miquel 1997: 322-323.

47 "Memorias de Cuba», ACZ, Fondo Personal de Francisco Sáenz de Urturi y Crespo, ff. 25-26.

48 Dámaso Sáenz de Urturi, sobrino del prelado que se desempeñaba como su capellán y mayordomo, pasó a ocupar la Secretaría del Arzobispado. Ibídem, ff. 16-17.
Honorable Presidente de la República Cubana» y elaborado según criterio de Manuel I. Mesa Rodríguez- nada menos que por los padres santiagueros Mustelier y Barnada..$^{49}$ La certeza de los clérigos de la cercana constitución del Estado nacional les llevó a exponer la conveniencia del establecimiento de iglesias nacionales. De este modo, garantizaban la confianza popular pues el catolicismo, «en inminente peligro de desaparecer de Cuba», no se salvaría con la «instrucción antipatriótica y antipolítica de un Clero extranjero». De hecho, su presencia se convertiría en «perpetuo germen de perturbación y discordia». Por tanto había llegado la hora de su renuncia "a la soberanía espiritual de un pueblo, que no es el suyo". La "Alta Presidencia del País" debía tener en cuenta que a la República Cubana le convenía y correspondía el establecimiento de Iglesias nacionales. ${ }^{50}$ Con respecto a la necesidad de prelados cubanos, el franciscano Sáenz de Urturi coincidía con los manifestantes.

Llama la atención, debido a la autoridad con que se pronunciaban en varios espacios públicos - al menos en Santiago-, la manera en que alegaban su «desaparición segura» de continuar la potestad de los eclesiásticos españoles. Ciertamente, al presentarse como "sufridos y perseguidos", "tolerados unos y vitandos otros», buscaban invalidar la permanencia de los prelados peninsulares que aún continuaban en la isla. A la postre, estos personificaban la experiencia colonial que solo les proporcionó "vejámenes", relegación y censura.

El 10 de agosto de 1898 Sáenz de Urturi le había referido al cardenal Rampolla sus temores sobre posibles venganzas personales «pues los odios y prevenciones contra cuanto a España [recordaba], se [acentuaba] cada día». Según alega, las pocas veces que salió de su edificio, fue objeto de improperios - «iQue hace aquí este español!, ipor qué no echamos de aquí este español!»- que le llevaron a su reclusión. ${ }^{51}$

En sus Memorias no deja de expresar los temores por la efervescencia popular que convirtió la ciudad en un espacio de reafirmación independentista. En la medida que el espacio público devenía escenario de rupturas simbólicas, se propiciaban actos de conducta violenta. En este sentido, la excitación -en algunas ocasiones- se concretó en una agresividad que se entremezclaba con las exaltaciones nacionalistas. Desde su aposento episcopal Sáenz de Urturi se mantenía al tanto de los acontecimientos y, retomando su diario, plasmaba episodios de tinte sangriento. Tales son los casos de la hostilidad pública hacia un grupo de guerrilleros que arribaron a la bahía santiaguera durante los meses de noviembre y diciembre. Según el prelado algunos terminaron muertos en las calles de Santiago «a pedradas, a palos y hasta a tiros»; mientras, otros españoles ni siquiera

49 La fecha del manifiesto data del 30 de septiembre de 1898. En el mismo se nombran 52 sacerdotes que, según los redactores, se adherían a los postulados. Para consultar el texto íntegro del manifiesto, véase Roig de Leuchsenring 1958: 47-52.

50 Ídem. Resulta interesante la visión del sacerdote Desiderio Mesnier sobre Sáenz de Urturi, publicada en La Independencia de Santiago de Cuba el 27 de noviembre de 1898. Esclarecer la necesidad de desespañolizar la Iglesia no le impidió defender al arzobispo español. En su criterio, la fidelidad de Sáenz de Urturi al gobierno colonial no fue óbice para estar a la altura de su misión. Era un prelado caritativo con todos y de intachable conducta. Consúltese Maza Miquel 2000: 242-246.

51 "Memorias de Cuba», ACZ, Fondo Personal de Francisco Sáenz de Urturi y Crespo, f. 24. 
pudieron desembarcar. Ante el ambiente perturbador, la policía y las autoridades interventoras recluyeron a muchos españoles en la Casa de gobierno o la cárcel, para así poder salvar sus vidas. Ello no fue óbice para el sentimiento popular, que se manifestaba frente a estas instituciones a gritos de «imueran los rabiosos!» y «imueran los españoles!».52

En la opinión del investigador católico Ramón Suárez Polcari, el prelado conocía poco a su "feligresía cubana» y debía «descubrir sus justos anhelos». ${ }^{53}$ La actitud de Sáenz de Urturi, para nada desconocedor de los sentimientos independentistas y de los movimientos liberales decimonónicos, refiere la comprensión de lo que, en su calidad de arzobispo español, representaba para la ciudad recién liberada. Amén de las posibles manipulaciones discursivas para justificar su salida de la ciudad, el proceso descolonizador que se efectuó en Santiago de Cuba escapa a los "prejuicios" del franciscano, si se percibe que a la capitulación le sucedió un tiempo inédito en el que las expresiones identitarias comprendieron -en algunos casos - la eliminación del individuo colonial. De hecho, el 25 de febrero de 1899 el delegado apostólico le refirió al cardenal Rampolla que si las tropas norteamericanas se retiraban, el arzobispo no podría quedarse en Santiago más de dos días. ${ }^{54}$

Si bien la exacerbación del nacionalismo insular dificultó el ministerio episcopal del franciscano, es una certeza que su comportamiento, al cerrar filas en el (re)sentimiento patriótico ante manifestaciones independentistas como procesiones cívicas y recibimientos masivos a figuras relevantes, solo incrementó el rechazo popular. Pese a que la presencia norteamericana dilataba la asunción plena de la soberanía, a los ojos de los ciudadanos la ocupación conllevó a la pacificación de la isla, la ruptura de los vínculos coloniales con España, a la vez que la expectativa de constituir un Estado nacional. De tal suerte, durante los primeros meses, se promovieron festejos en los que se celebraba la retirada de las fuerzas españolas desde el fortalecimiento de la identidad nacional. La bandera norteamericana enarbolada en muchos lugares se consideraba como un símbolo de la liberación de España. ${ }^{55}$

El 22 de septiembre de 1898 hizo su entrada solemne en la plaza el general Calixto García. Mientras la ciudad se estremecía en el "entusiasmo patriótico», las ventanas del Palacio arzobispal permanecieron cerradas y en la noche, las casas iluminadas contrastaban con la morada del arzobispo, a oscuras "para patentizar la tristeza de sus moradores». En las líneas de las Memorias donde Urturi hace alusión al hecho se refleja la mentalidad colonialista entretejida como resultado de cuatro siglos de hegemonía española sobre Cuba. Para él, Calixto García era un "indito" que se disponía, con sus "abigarradas hordas», a entrar triunfante en "la ciudad de Diego Velázquez». ${ }^{56}$

52 "Memorias de Cuba», ACZ, Fondo Personal de Francisco Sáenz de Urturi y Crespo, f. 19, f. 24 y f. 30. Para consultar ejemplos de las manifestaciones públicas, véase: Bacardí y Moreau 1924: 185-187 y 204. Con respecto a la interpretación del arzobispo sobre el comportamiento de los cubanos, consultar la carta que envió al cardenal Rampolla el 28 de noviembre de 1898. Maza Miquel 1997: 333.

53 Suárez Polcari 2003: 178.

54 Maza Miquel 2007: 322-323 y 507-508.

55 Mesa Redonda entre historiadores cubanos. 1997. «Significación del 98». Debates Americanos 4: 191.

56 "Memorias de Cuba», ACZ, Fondo Personal de Francisco Sáenz de Urturi y Crespo, ff. 21-22.
Así, la edificación se convirtió en un símbolo de la memoria colonialista cada vez que la ciudad era escenario de homenajes independentistas. Tales fueron los casos de las conmemoraciones de los aniversarios del 10 de octubre y el 24 de febrero cuando, a las actitudes de moradores que engalanaron con banderas cubanas algunas ventanas del Palacio arzobispal, el prelado respondió retirando los estandartes. Su comportamiento era coherente con un pensamiento que definía aquellos sucesos como "patriotismo exagerado y mal entendido». ${ }^{57}$ Su actitud contrastaba con la conducta del sacerdote cubano Desiderio Mesnier quien, en el marco de la primera de ambas conmemoraciones, dirigió una alocución independentista al pueblo.

Durante el primer año de ocupación, el paradigma de las ceremonias religiosas que simboliza la desvertebración de la Iglesia (pen)insular ${ }^{58}$ se representa en las honras fúnebres por el alma del mayor general Antonio Maceo, celebradas en la Catedral Metropolitana. En el contexto santiaguero, la solemnidad, a la vez conmemoración popular, constituye un principio de la readecuación institucional eclesiástica a la afirmación nacionalista. El tributo rendido a Maceo en la Basílica de Santiago muestra que, si bien la Iglesia Católica había perdido la connotación político-social que ostentó bajo el régimen colonial, continuaba figurando como depositaria de la tradición insular y símbolo de legitimación cultural.

Desde la víspera del 7 de diciembre de 1898 en la iglesia más representativa de la arquidiócesis oriental cimbraban las campanas a la usanza colonial: con 50 dobles Antonio Maceo recibía los honores fúnebres de un Capitán General de la Colonia y desde el atrio se enumeraban "las grandes virtudes del hijo insigne de Santiago".$^{59}$ Las naves de la catedral atestadas de personas y la presencia del clero cubano junto a grandes oficialidades de la independencia contrastaban con el sitio vacío de la silla arzobispal. Sáenz de Urturi, que había rechazado el ofrecimiento de asistir de pontifical y pronunciar la oración fúnebre, permaneció recluido en su palacio, dando muestras de no asociarse a los sentimientos patrióticos de los cubanos. En este sentido, el hecho en su amplitud ejemplifica las contradicciones identitarias que marcaron el ministerio episcopal de Sáenz de Urturi ante el cambio de dominación.

Su completo desapego de la realidad insular lo hizo manifiesto al cardenal Rampolla en la comunicación enviada el 25 de febrero de 1899, con la intensión de reafirmar la obligación de poner término a su gobierno arzobispal. Entre las razones aludidas, claro está, cobró un peso importante el ambiente antiespañol que prevalecía en la ciudad, no obstante, al franciscano no le tembló la pluma para plantear que:

Solo veo en Cuba los enemigos de mi patria; los que la han abofeteado, los que la han humillado, hasta el extremo de hallarse hoy al borde del abismo. España es mi madre; cuanto más humillada la veo, más debo

57 Esta definición de Sáenz de Urturi en torno a las manifestaciones del nacionalismo cubano puede leerse en su carta al cardenal Rampolla del 25 de febrero de 1899. Tomada de: Maza Miquel 1997: 510.

58 Por Iglesia (pen)insular se define la Iglesia Católica en Cuba desde mediados del siglo XIX. La institución se encontraba vertebrada al poder español por la composición mayoritaria de clérigos, obispos, arzobispos, órdenes religiosas hispanas y por la defensa de los intereses de los gobiernos peninsulares.

59 Bacardí y Moreau 1924: 200-201. 
amarla. Tengo que por lo tanto que hallarme en este estado de constante violencia [...]. Un obispo que no siente amor hacia sus diocesanos, es obispo muerto: en tal estado me encuentro yo [...]. Cuanto haga será frio, será hijo sólo de la inteligencia, no del corazón, y lo que en la misión episcopal no nace del corazón, nace muerto $\left[\ldots . . . .^{60}\right.$

Coherente con su ética sacerdotal, para el prelado era primordial el ministerio de un sacerdote que se correspondiese con la sociedad insular y sobre esta base defendiera los intereses de la institución eclesiástica ante el nuevo estado que, si bien indefinido, no se sustentaría sobre la vertebración con la Iglesia Católica.

Las señales de los tiempos aceleraban el fin del arzobispo en Cuba. Desde la isla veía desmoronarse el poder colonial que representaba, a la vez que su estado de salud flaqueaba. En reunión de la Sagrada Congregación para Asuntos Extraordinarios de la Iglesia, la renuncia de Sáenz de Urturi se presentaba condicionada en sus perfiles médicos y psicológicos. Era la decisión de un «hombre enfermo, mal visto y desanimado». ${ }^{61}$ El 2 de abril de 1899 el Vaticano envió la aceptación oficial de la abdicación de su prelado. Al día siguiente Francisco de Paula Barnada y Aguilar comenzó a encargarse del gobierno eclesiástico, como le propuso Sáenz de Urturi al cardenal Rampolla en todas sus comunicaciones. ${ }^{62}$

Amén de los anteriores argumentos, era evidente que el resentimiento de tipo nacionalista, piedra de toque de su actitud, debió ejercer gran presión en la Sagrada Congregación, pues poco favorecería a la evolución de la Iglesia Católica en el nuevo contexto insular. En las actitudes del prelado se ratificó el axioma que identificaba e integraba en un todo indisoluble catolicismo e hispanidad. También los tiempos requerían de nuevos consensos y de una política eclesial más ajustada a las relaciones con la excolonia en el contexto posbélico. Mientras tanto, como símbolo del poder hispano distanciado en el Atlántico, el franciscano español se alejaba de la isla para recluirse en el Convento de Zarauz, Guipúzcoa, por el resto de sus días. En el silencio monacal que tanto anheló se dedicó a escribir sus Memorias de Cuba, entre los documentos más importantes y desconocidos para el tratamiento de este postrer episodio de la dominación colonial en Cuba.

\section{FUENTES}

\section{Documentales:}

\section{Archivo Provincial de Santiago de Cuba}

Libro de Actas del Consejo de Vecinos (1898-1899).

Gobierno Municipal (sin procesar).

\section{Archivo del Museo Emilio Bacardí de Santiago de Cuba}

60 Anterior a la fecha, el 28 de noviembre de 1898 el arzobispo le había manifestado al cardenal Rampolla que era inconciliable su permanencia al frente de la mitra oriental. Consúltese el texto íntegro de la comunicación en: Maza Miquel 1997: 509-514.

61 Maza Miquel 1997: 333 y 339.

62 Sobre la formación académica y carrera eclesiástica de Francisco de Paula Barnada y Aguilar, consúltense las denominadas Letras testimoniales expedidas por Francisco Sáenz de Urturi el 23 de agosto de 1898 en: AHASC, Gobierno, Serie Clero, leg. 60, no. 80, ff. 184-186.
Fondo Emilio Bacardí: legajo 31.

Archivo del Convento de Zarauz, Guipúzcoa, España

Fondo Personal de Francisco Sáenz de Urturi y Crespo, "Memorias de Cuba".

Archivo Histórico Arquidiocesano de Santiago de Cuba Sección Gobierno

Serie Hospitales, Asilos, Conventos e Instituciones: Legajo 28.

Serie Religiosos: Legajos 14 y 25.

Serie Clero: Legajos 37 y 60.

Archivo del Museo Catedral de Santiago de Cuba.

Libro de Acuerdos del Ilustrísimo Cabildo en Sesiones.

«Acta de la primera festividad religiosa en Cuba independiente».

Hemerográficas: 1894.

Boletín Oficial del Arzobispado de Santiago de Cuba,

Cuba y América, 1898.

Debates Americanos, 1997.

La Independencia, 1898.

Digitales:

Catálogo cronológico por diócesis, en: http://www. catholic-hierarchy.org/

\section{BiBLIOGRAFÍA}

Bacardí y Moreau, E. 1924. Crónicas de Santiago de Cuba. Santiago de Cuba: Tipografía Arroyo Hermanos.

Castellanos, J. G. 1950. «Emilio Bacardí Moreau», en Figuras Nacionales: 29-32. Manzanillo: Editorial El Arte.

González del Valle, F. 1918. «El clero en la revolución cubana». Cuba Contemporánea 2, octubre.

Hernández Suárez, Y. 2010. Iglesias cristianas en Cuba entre la independencia y la intervención. La Habana: Editora Historia.

Iglesias Utset, M. 2003. Las metáforas del cambio en la vida cotidiana: 1898-1902. La Habana: Ediciones Unión.

Larrúa Guédes, S. 2004. Cinco Siglos de Evangelización Franciscana en Cuba. Carolina: Custodia Franciscana del Caribe.

Maza Miquel, M. 1997. Entre la ideología y la compasión. Guerra y paz en Cuba 1895-1903. (Testimonios de los Archivos Vaticanos). Santo Domingo: Instituto Pedro Francisco Bonó.

Maza Miquel, M. 2000. Esclavos, patriotas y poetas a la sombra de la cruz. Cinco ensayos sobre catolicismo e historia cubana. Santo Domingo: Instituto Pedro Francisco Bonó.

Meza, R. 1902. «Parques públicos». Cuba y América 109: 313.

Pichardo, H. 1973. Documentos para la Historia de Cuba. La Habana: Editorial de Ciencias Sociales.

Roig de Leuchsenring, E. 1958. La iglesia católica y la independencia de Cuba. La Habana: Gran Logia de Cuba A. L y A. M.

Segreo Ricardo, R. 2010. Iglesia y Nación en Cuba (1868-1898). Santiago de Cuba: Editorial Oriente.

Suárez Polcari, R. 1996 «Participación de la Iglesia Católica durante la Guerra de Independencia 1895-1898». Raíz y Ala 2.

Suárez Polcari, R. 2003. Historia de la Iglesia Católica en Cuba. Miami: Ediciones Universal.

Uría, I. 2016. Bajo dos banderas, Religión y política en Cuba durante la primera ocupación americana (1899-1902). Pamplona: Eunsa. 